\title{
POLA KOMUNIKASI BARISTA DENGAN COSTUMER DI COFFE SHOP COCONUDE BEVERAGES SWEETENED BANDUNG
}

\author{
Nadhia Hila Aufa ${ }^{1}$, Adi Permana Sidik ${ }^{2}$ \\ 1,2 Universitas Sangga Buana \\ ${ }^{1}$ korespondensi: hilaaufanadhia@gmail.com
}

\begin{abstract}
This study was conducted to determine the pattern of communication between baristas and customers at Coconude Beverages Sweetened Jalan Wira Angun Angun No. 15 Bandung City. As for what underlies the researchers doing this research because coffeeshops throughout the archipelago, in serving their customers they use waiters or a waiter, if a customer wants to order something, they call waiters. Unlike the Coconude Sweetended Beverages coffeeshop, they use a Barista to serve or communicate directly with customers. If the customers want to order something they have to approach the bar to order the menu that the customer wants. This research uses qualitative method with descriptive research type. Perform data collection techniques by observation, in-depth interviews (indepth interviews) and documentation. The data analysis techniques used in this research are data reduction, data presentation, and conclusion drawing. The results of this study are. (1) The communication used by the barista with the customer is verbal and nonverbal communication. (2) The media used to communicate are the five senses consisting of eyes and ears (3) The effects obtained by baristas and customers are cognitive and conative.
\end{abstract}

Keywords: Verbal and Nonverbal Communication, Communication Pattern, Barista

\begin{abstract}
ABSTRAK
Penelitian ini dilakukan untuk untuk mengetahui pola komunikasi antara barista dengan customer di Coconude Beverages Sweetened Jalan Wira Angun Angun No. 15 Kota Bandung. Adapun yang mendasari peneliti melakukan penelitian ini karena coffeeshop diseluruh penjuru nusantara, dalam melayani customer mereka menggunakan waiters atau seorang pelayan, jika seorang customer ingin memesan sesuatu, mereka memanggil waiters. Berbeda dengan coffeeshop Coconude Sweetended Beverages, mereka menggunakan Barista untuk melayani atau berkomunikasi langsung dengan customer. Jika para customer ingin memesan sesuatu mereka harus menghampiri bar untuk order menu yang customer inginkan. Penelitian ini menggunakan metode kualitatif dengan jenis penelitian deskriptif. Melakukan teknik pengumpulan data dengan observasi, wawancara mendalam (indepth interview) dan dokumentasi. Teknik analisis data yang digunakan dalam penbelitian ini adalah adalah reduksi data, penyajian data, penarikan kesimpulan. Hasil penelitian ini adalah. (1) Komunikasi yang digunakan oleh barista dengan customer yaitu komunikasi verbal dan nonverbal. (2) Media yang digunakan untuk berkomunikasi ialah pancaindera yang terdiri dari mata dan telinga (3) Effect yang didapatkan oleh barista dan customer adalah kognitif dan konatif.
\end{abstract}

Kata Kunci: Komunikasi Verbal dan nonverbal, Pola Komunikasi, Barista

\section{PENDAHULUAN}

Komunikasi merupakan bagian yang tidak terpisahkan dari kehidupan sehari-hari khususnya pada manusia. Komunikasi menjadi alat untuk berinteraksi dengan orang lainnya. Manusia sangat membutuhkan komunikasi. Dengan kata lain manusia tidak bisa untuk tidak berkomunikasi. Cara seseorang individu atau kelompok berkomunikasi disebut dengan pola komunikasi. Pola komunikasi merupakan proses yang disusun sebagai representasi realitas keterpautan antar unsur yang melingkupinya beserta keberlangsungannya, untuk memudahkan pemikiran secara logis dan sistematis [1]. Pola komunikasi selalu berkaitan dengan bagaimana orang tersebut berkomunikasi dengan individu 
lainnya. Pola komunikasi pada dasarnya adalah sebuah proses. Yang dimaksud dengan proses itu sendiri yaitu interaksi dan transasksi. Transaksi yang terlibat terkait dengan ide, pesan, simbol atau informasi. Sedangkan arti dari interaksi sendiri adalah suatu tindakan yang menimbulkan timbal balik. Pola komunikasi sendiri memiliki beberapa jenis yang terdiri dari primer, sekunder, linier dan sirkular [1].

Komunikasi memegang peranan yang sangat penting dalam kehidupan, oleh karena itu komunikasi dapat digunakan sebagai perantara atau sebagai sarana penyampaian informasi, yang dimana kegiatannya berhubungan dengan orang lain saat menjalankan tugas. Dalam beberapa bidang, sangat penting untuk menjaga komunikasi yang efektif. Komunikasi yang efektif saat menjalankan bisnis merupakan faktor penting untuk kesuksesan bisnis. Melalui komunikasi yang baik, pelaku bisnis dapat menjual produknya dengan baik dan menghindari kesalahpahaman dengan patner kerja atau pelangganya. rekan bisnis atau konsumennya. Ketika berbisnis, misalnya marketing diperlukan komunikasi yang efektif khususnya dengan pelanggan agar produknya dapat diterima secara maksimal.

Coffee shop atau disebut dengan usaha (bisnis) kopi di Indonesia bisa disebut terus meningkatnya perkembangannya. Sebagai contoh, Starbucks sebuah brand dari negeri Paman Sam mucul di Indonesia sejak tahun 2001. Belakangan, bisnis kopi mulai menyebar di berbagai Kawasan di Indonesia, termasuk di
Bandung. Sebagai ibu kota di Jawa Barat, di tota Bandung terbanyak kedai kopi (coffe shop). Kedai kopi tersebut biasanya menjadi pilihan bagi kalangan muda sebagai lokasi untuk berkumpul. Bandung memiliki banyak tempat yang menawarkan jasa minuman berbahan dasar kopi yang tentunya akan berdampak pada persaingan pasar. Persaingan di antara bisnis sejenis semakin sengit, dan pemilik kedai kopi berencana mengembangkan berbagai cara mempertahankan pelanggan, yaitu dengan meningkatkan kualitas layanan kepada konsumen. Dalam hal peningkatan pelayanan sekaligus menjaga agar bisnis kedai kopi tetap berdaya saing tinggi, peran barista (penanggung jawab pencampuran dan penyeduhan) memiliki peran utama dan sangat vital dalam agar konsumen tetap setia.

Seorang Barista perlu mempunyai skill komunikasi yang mumpuni agar melahirkan kenyamanan konsumennya. Saat berkomunikasi, keterampilan komunikasi yang diperlu dimiliki seorang Barista yaitu pola komunikasi. Pola komunikasi semakna dengan proses komunikasi. Mengap demikian? Karena dalam proses komunikasi akan melahirkan pola komunikasi. Proses komunikasi adalah susunan kegiatan yang digunakan untuk menyampaikan pesan untuk menghasilkan umpan balik dari komunikan Dengan adanya proses komunikasi inilah seorang Barista dan seorang pelanggan menghasilkan satu bentuk pola komunikasi dan juga bagian lain yang saling terkait dalam sebuah proses komunikasi. Tak heran coffeeshop diseluruh 
penjuru nusantara, dalam melayani customer mereka menggunakan waiters atau seorang pelayan, jika seorang customer ingin memesan sesuatu, mereka memanggil waiters. Berbeda dengan coffeeshop Coconude Sweetended Beverages, mereka menggunakan Barista untuk melayani atau berkomunikasi langsung dengan customer. Jika para customer ingin memesan sesuatu, mereka harus menghampiri bar untuk order menu yang customer inginkan.

Dari fenomena tesebut, peneliti tertarik untuk meneliti mengenai pola komunikasi antara barista dengan customer. Tingkat kenyamanan customer dipengaruhi oleh layanan yang diberikan oleh seorang barista. Kenyamanan pelanggan adalah tingkat perasaan setelah membandingkan antara harapan yang diterima pelanggan sesuai atau tidak. Kenyamanan yang dirasakan oleh pelanggan ditimbulkan dari proses komunikasi seorang Barista kepada pelanggan tersebut, misalnya kegiatan pelayanan di Coconude Bandung. Komunikasi Barista memiliki peran yang vital ketika berkomunikasi dengan pelanggan. Barista harus memiliki kemampuan komunikasi yang efektif untuk membuat pelanggan terkesan. Dengan begitu, keberadaan coffee shop akan tetap terjaga.

\section{TINJAUAN PUSTAKA}

\section{Pola Komunikasi}

Pola komunikasi yang dimaksud pada artikel ini yaitu cara kerja suatu kelompok atau individu ketika melakukan aktivitas komunikasi [2]. Memahami pola komunikasi ini bisa digambarkan seperti ketika seseorang merancang pakaian (kaos). Ketika akan merancang desain pakaian, terlebih dahulu menyusun pola (pattern). Pola biasanya masih bersifat fleksibel, bisa berubah-ubah setiap saat sesuai kebutuhan. Pola yang sudah dibuat menentukan pilihan bentuk atau model sebuah kaos. Setelah melalui beberapa proses, kaos akan terlihat jelas model dan bentuknya. Dari gambaran tersebut, pola komunikasi dapat dimaknasi sebagai wujud komunikasi yang fleksibel, mudah berubah. Pola tersebut dipengaruhi oleh berbagai simbol bahasa yang biasanya oleh berbagai kelompok telah disepakati dan digunakan.

\section{Barista}

Barista bermakna seseorang bekerja mengolah dan menyajikan kopi kepada pelanggan. Istilah Barista sendiri berasal dai bahasa Italia yang diartikan sebagai aktivitas khusus dalam mengolah dan menyediakan espresso dan minuman yang berbasis espresso. Barista mengolah kopi menggunakan mesin kopi dan menyediakan beragam menu denga kopi sebagai bahan dasarnya. Selain itu, seorang Barista perlu memiliki kemampuan membuat kopi yang reguler (manual brew). Intinya, Barista memiliki pekerjaan yang cukup rumit dari sekadar penyedia minuman biasa [3].

\section{METODE PENELITIAN}

Artikel ini menggunakan metode penelitian kualitatif. Sugiyono mengatakan bahwa 
penelitian kualitatif merupakan penelitian yang menempatkan peneliti sebagai instrumen kunci. Pengumpulan data-data dilakukan dengan cara mengggabungkan analisis data dan biasanya bersifat induktif.[4] Kirk dan Miller menjelaskan penelitian kualitatif sebagai usaha melakukan obseevasi secara langsung pada individu tertentu guna memperoeh data yang akan di dalami.[5]

Sementara Sugiyono[6], mengatakan bahwa analisis deskriptif adalah statistik yang digunakan untuk mengalisis data dengan cara mendeskripsikan atau menggambarkan data yang telah terkumpul sebagaimana adanya tanpa bermaksud membuat kesimpulan yang berlaku untuk umum atau generalisasi [6].

Sesuai dengan permasalahan yang menjadi fokus dalam penelitian ini yaitu gambaran deskriptif mengenai pola komunikasi antara Barista dengan Pelanggan di Coconude Bandung, maka peneliti menggunakan pendekatan kualitatif dengan mendeskripsikan data yang peneliti peroleh sebagai hasil suatu penelitian. Dengan menggunakan metode ini, maka peneliti akan mendapatkan data secara utuh dan dapat dideskripsikan dengan jelas sehingga hasil penelitian ini benar-benar sesuai dengan kondisi lapangan yang ada.

\section{HASIL DAN PEMBAHASAN}

Komunikasi Verbal dan Nonverbal di

\section{Coconude}

Komunikasi merupakan hal yang tidak asing bagi manusia atau makhluk sosial, seperti yang kita ketahui manusia tidak bisa hidup tanpa berkomunikasi. Dalam konteks komunikasi, ada dua bentuknya, yang dikenal dengan komunikasi verbal dan nonverbal[7].

Tujuan pertama dalam penelitian ini adalah untuk mengetahui bagaimana komunikasi verbal dan nonverbal antara barista dengan customer di Coconude. Di Coconude, barista dengan customer berinteraksi secara langsung tanpa perantara apapun, karena agar tidak terjadi miss communication dalam pemesanan. Dari hasil wawancara dengan Head Barista Coconude yaitu Arviandri Ramadhan Loe, barista berkomunikasi langsung dengan customer dirasa sangat efektik, karena live communication, jadi komunikasi secara langsung dua arah dengan customer agar lebih praktis dan juga tidak terjadi miss communication. Menurut Arni[8] dalam bukunya yang berjudul Komunikasi Organisasi Komunikasi verbal yaitu komunikasi yang menggunakan simbol-simbol atau kata-kata, baik yang dinyatakan oral atau lisan maupun secara tulisan.[8] Anjaswari[9] mengungkapkan bahwa komunikasi oral adalah komunikasi yang dilakukan secara lisan, baik langsung dengan cara tatap muka maupun secara tidak langsung.[9] Barista Coconude menuturkan ketika customer pertama kali berkunjung ke kedai Coconude, mereka kebingungan untuk memesan apa. Barista harus punya kepekaan dan cepat menangkap ekspresi custumer, dan berikutnya menawarkan menu yang cocok. Ketika sudah terlalu lama memilih menu, Barista berinisiatif menawarkan pilihan menu yang sesuai atau cocok, kemudian menjelaskan menu 
yang dimaksud si customer. Jika customer tersebut tidak paham, dan menanyakan customer ingin minuman seperti apa [9]

Anjaswari[9] melanjutkan komunikasi tertulis merupakan komunikasi yang berlangsung atau terjadi dalam bentuk tulisan manual dan elektronik, yang bertujuan memberikan informasi.[9] Dalam menggunakan komunikasi tertulis, Barista Coconude mengutarakan jika ia pernah berkomunikasi dengan customer menggunakan tulisan. Ketika melayani customer yang memiiki kebutuhan khusus seperti tuna wicara, Barista berkomunikasi secara tertulis dengan medium alat tulis buku dan ballpoint. Artinya, komunikasi anatar Barista dan customer terjadi melalui medium tulisan. Selain komunikasi verbal, ada juga komunikasi nonverbal. Mashudi[10] menuturkan komunikasi nonverbal adalah proses komunikasi yang tidak menggunakan kata-kata dalam penyampaian pesan. Salah satu bentuk komunikasi nonverbal ialah gestur tubuh dan ekspresi wajah. [10]. Ekman dan Friesen dalam Mashudi[10] mengklasifikasi gerakan tubuh menrutu fungsi, asal, dan maknanya sebagai berikut:

1) Emblems, adalah gerakan yang menggantikan kata dan kalimat. Dalam menggunakan Emblems, customer di Coconude mengatakan bahwa mereka seringkali memanggil barista dengan hanya mengacungkan atau melambaikan tangan, dan wajahnya mengarah ke Barista tersebut yang artinya si customer memanggil Barista dan meminta untuk menghampiri customer tersebut. Customer di Coconude juga menjelaskan bahwa Barista sudah mengerti dengan apa yang dimaksud dan langsung menghampiri pelanggan.

2) Ilustrators, gerakan yang mendampingi untuk memperkuat pesan verbal. Dalam menggunakan Ilustrators, Barista di Coconude menjelaskan bahwa ketika customer sedang memesan menu, dan barista menanyakan atau mengkonfirmasi terkait pesanan yang ia pesan, dan si customer tersebut menganggukan kepala sambil berkata "iya". Dan ketika si barista memastikan lagi “Ada tambahan lagi Kak?”, customer menjawab "tidak" sambil menggelengkan kepala [10].

Hasil observasi pada komunikasi verbal yang dilakukan oleh Barista dan customer di Coconude, merupakan komunikasi secara langsung atau bertatap muka dan menghasilkan sebuah feedback, yang dimana ketika seorang customer menghampiri bar untuk memesan minuman atau makanan, dan menanyakan terkait menu yang tertera, disitulah terjadi komunikasi verbal yang terjadi antara barista dengan customer. Selain komunikasi verbal, hasil obeservasi pada komunikasi nonverbal yang dilakukan oleh Barista dan customer di Coconude, merupakan komunikasi tanpa menggunakan kata-kata atau bisa disebut juga dengan gerakan tubuh, bahasa tubuh, kedipan mata dan lainnya, yang dimana ketika seorang customer sudah mendapatkan tempat duduk, dan 
merasa perlu tambahan atau complain, ketika itu customer mengacungkan tangan dan mengarah ke seorang barista, dan disitulah terjadi kontak mata antara barista dan customer, sehingga seorang barista pun langsung menghampiri karena merasa terpanggil [10].

\section{Media yang digunakan Barista Coconude}

Tujuan kedua pada penelitian ini yaitu mengetahui media yang dipakai Barista saat berkomunikasi dengan customer. Seperti yang diketahui, Coconude merupakan coffeeshop yang memiliki aturan service barista dengan customer berkomunikasi langsung. Maka dari itu, Media merupakan hal yang sangat penting untuk barista dalam berkomunikasi. Lasswell menyampaikan dari lima unsur dalam proses komunikasi yang ia definisikan, salah satunya yaitu media. Media yang dimaksud di sini adalah alat yang digunakan untuk memindahkan pesan dari sumber kepada penerima.[11]-[13] Di Coconude, dalam menggunakan media untuk berkomunikasi adalah menggunakan pancaindera mata dan telinga. Dalam menggunakan mata, barista dan customer melakukan kontak mata ketika sedang memesan menu, atau ketika customer memanggil barista dengan cara mengacukan tangannya sambil melihat ke arah barista lalu disitu terjadi kontak mata antara barista dengan customer.

Selain mata, barista dan customer coconude menggunakan media pancaindera telinga. Ketika customer memesan menu, dan mereka tidak begitu mengerti dengan menu tersebut "kalo original sweetened itu apa ya mas?", maka barista akan menjelaskan kepada customer tentang menu terkait, dan customer mendengar apa yang dijelaskan oleh barista. Selain itu, ketika customer memesan menu yang akan dia pesan, barista menggunakan telinga sebagai alat komunikasinya yaitu mendengarkan apa yang customer bicarakan.

\section{Effect yang Didapatkan Barista dan Customer}

\section{Coconude}

Tujuan ketiga pada penelitian ini adalah mengetahui effect yang didapatkan barista dengan customer Coconude. Menurut Purwasito pola komunikasi dalam artikrl ini yaitu cara kerja individu atau kelompok saat berkomunikasi. Pola komunikasi memiliki beberapa jenis, salah satunya adalah pola komunikasi sirkular, salah satu pola yang digunakan untuk menggambarkan proses komunikasi adalah pola sirkuler yang dibuat oleh Osgood bersama Schramm. Pola ini menggambarkan komunikasi sebagai proses yang dinamis, di mana pesan ditranmisit melalui proses encoding dan decoding. Encoding adalah transilasi yang dilakukan oleh sumber atas sebuah pesan, dan decoding adalah transilasi yang dilakukan oleh penerima terhadap pesan yang berasal dari sumber. Hubungan antara encoding dan decoding adalah hubungan antara sumber dan penerima secara stimultan dan saling mempengaruhi satu sama lain. Pada tahap awal, sumber berfungsi sebagai encorder dan penerima sebagai decorder. Tetapi 
pada tahap berikutnya penerima berfungsi sebagai pengirim (encorder) dan sumber sebagai penerima (decorder), dengan kata lain sumber pertama akan menjadi penerima kedua dan penerima pertama berfungsi sebagai sumber kedua, dan seterusnya.

Dalam menggunakan pola komunikasi sirkular, Barista Coconude mengungkapkan tak jarang juga customer yang tidak mengerti dengan menu yang tertera. Customer kebingungan dan bertanya kepada barista tentang menu tersebut, lalu barista menjelaskan terkait menu yang dimaksud oleh customer, pada tahap awal disini barista berperan sebagai encoder atau pengirim pesan dan customer berperan sebagai decorder atau penerima pesan. Ketika customer sudah mengerti apa yang dijelaskan oleh barista, kemudian customer memesan menu kepada barista. Pada tahap kedua ini, customer berperan sebagai encoder atau pengirim pesan dan barista berperan sebagai decorder atau penerima pesan. Keduanya saling berhubungan dan terjadi pola komunikasi sirkular.

Customer di Coconude juga mengatakan, bahwa ketika mereka mengunjungi Coconude untuk pertama kalinya dan tampak bingung, barista Coconude menghampiri dan bertanya apakah ada yang bisa dibantu atau tidak. Kemudian customer bertanya apakah sistem di Coconude langsung memesan atau mencari tempat duduk dahulu. Barista tersebut menjelaskan bahwa keduanya bisa saja dilakukan dan Coconude tidak memiliki aturan yang akurat seperti itu. Pada tahap awal disini, barista berperan sebagai encoder atau pengirim pesan, sedangkan customer berperan sebagai decorder atau penerima pesan. Customer berkata kepada barista bahwa ia memilih memesan menu terlebih dahulu. Pada tahap kedua disini, customer berperan sebagai encoder atau pengirim pesan, sedangkan barista berperan sebagai decoder atau penerima pesan. Dan disitulah terjadi pola komunikasi sirkular. Dalam effect ini terdapat 3 tataran yang diantaranya adalah kognitif, afektif dan konatif. Kognitif disebut juga sebagai seseorang menjadi tahu sesuatu. Di Coconude selalu ada customer yang tidak mengerti dengan menu yang tertera. Customer kebingungan dan bertanya kepada barista tentang menu tersebut, lalu barista menjelaskan menu terkait. Jika customer belum paham dengan yang dijelaskan oleh barista maka mereka akan bertanya lagi. Dan jika customer sudah mengerti maka mereka mengangguk mengerti dan langsung memesan menu tersbut. Disini customer menjadi tahu terkait menu tersebut dan hal ini disebut kognitif.

Selain kognitif, ada juga yang disebut konatif yaitu tingkah laku atau hal yang membuat seseorang bertindak melakukan sesuatu. Barista Cocondue dalam membuatkan pesanan customer tidak jarang melakukan kesalahan, misalnya membuat menu yang salah atau saat flow-nya sangat cepat, lupa untuk membuatkan pesanan. Ketika salah membuat pesanan, otomatis akan diganti dengan menu baru dan memberikan free snack sebagai wujud 
permintaan maaf. Saat itu terjadi, Barista minta tetap tenang dan memberikan pemahaman kepada customer. Artinya Barista bertindak melakukan sesuatu atas kesalahannya dan hal ini disebut konatif.

\section{KESIMPULAN}

Berdasarkan paparan di atas mengenai hasil penelitian serta pembahasannya, maka dapat ditarik kesimpulan sebagai berikut.

1. Komunikasi verbal dan nonverbal di Coconude yakni barista berkomunikasi langsung dengan customer dirasa sangat efektik, karena live communication, jadi komunikasi secara langsung dua arah dengan customer agar lebih praktis dan juga tidak terjadi miss communication. Pada saat ini, suatu coffee shop sudah tak lumrah dalam menggunakan barista untuk melayani customernya secara lain. Selain lebih praktis, barista juga bisa memberikan informasi secara langsung mengenai menu yang dipesan oleh customer, baik biji kopinya dari jenis apa, ataupun cara mengolahnya seperti apa. Selain komunikasi verbal komunikasi nonverbal yang dilakukan oleh Barista dan customer di Coconude, merupakan komunikasi tanpa menggunakan kata-kata atau bisa disebut juga dengan gerakan tubuh, bahasa tubuh, kedipan mata dan lainnya, yang dimana ketika seorang customer sudah mendapatkan tempat duduk, dan merasa perlu tambahan atau complain, ketika itu customer mengacungkan tangan dan mengarah ke seorang barista, dan disitulah terjadi kontak mata antara barista dan customer, sehingga seorang barista pun langsung menghampiri karena merasa terpanggil.

2. Media yang digunakan barista dengan customer untuk berkomunikasi menurut bentuknya ialah pancaindera mata dan telinga. Coconude merupakan coffeeshop yang memiliki aturan service barista dengan customer berkomunikasi langsung. Dalam menggunakan mata, barista dan customer melakukan kontak mata ketika sedang memesan menu, atau ketika customer memanggil barista dengan cara mengacukan tangannya sambil melihat ke arah barista lalu disitu terjadi kontak mata antara barista dengan customer. Dalam menggunakan telinga, ketika customer memesan menu yang akan dia pesan, barista menggunakan telinga sebagai alat komunikasinya yaitu mendengarkan apa yang customer bicarakan.

3. Effect yang didapatkan oleh barista dan customer di Coconude yaitu kognitif dan konatif. Yang dimana, barista Coconude mengungkapkan tak jarang juga customer yang tidak mengerti dengan menu yang tertera. Customer kebingungan dan bertanya kepada barista tentang menu tersebut, lalu barista menjelaskan terkait menu yang dimaksud oleh costumer, pada tahap awal disini barista berperan sebagai encoder atau 
pengirim pesan dan customer berperan sebagai decorder atau penerima pesan. Ketika customer sudah mengerti apa yang dijelaskan oleh barista, kemudian customer memesan menu kepada barista. Pada tahap kedua ini, costumer berperan sebagai encoder atau pengirim pesan dan barista berperan sebagai decorder atau penerima pesan. Keduanya saling berhubungan dan terjadi pola komunikasi sirkular.

\section{DAFTAR PUSTAKA}

[1] O. U. 1993 Effendy, Dinamika Komunikasi. Bandung: Remaja Rosdakarya, 1993.

[2] A. Purwastio, Komunikasi Multikurtural. Yogyakarta: Pustaka Pelajar, 2015.

[3] F. Ramadhan, "Makna Kerja Sebagai Barista," Skripsi, vol. 53, no. 9, 2016.

[4] Sugiyono, Memahami penelitian kualitatif. 2014/Sugiyono. 2014.

[5] L. J. Moleong, "Metodologi Penelitian
Kualitatif (Edisi Revisi)," in PT. Remaja Rosda Karya, 2017.

[6] Sugiyono, Metode Penelitian Kualitatif. Bandung: Alfabeta, 2020.

[7] C. Chotimah and M. Fathurrohman, Komplemen Manajemen Pendidikan Islam. Yogyakarta: Teras, 2014.

[8] A. Muhammad, Komunikasi Organisasi. Jakarta: Bumi Aksara, 2011.

[9] M. K. Tri Anjaswarni, S.Kp., Komunikasi dalam Keperawatan Komperehensif. 2016.

[10] F. Mashudi, Psikologi Konseling. Yogyakarta: Diva Press, 2012.

[11] H. Cangara, Pengantar Ilmu Komunikasi (Edisi Kedua). 2016.

[12] D. Mulyana, Ilmu Komunikasi: Suatu Pengantar. Cetakan ke 18. 2007.

[13] H. Sabar, T. Bahfiarti, R. Aini, M. Budyatna, and L. M. Ganiem, "Teori Komunikasi AntarPribadi," J. Ilmu Komun., vol. 9, no. 1, 2011. 